\title{
Adult-onset autosomal recessive cerebellar ataxia
}

INSERM

\section{Source}

INSERM. (1999). Orphanet: an online rare disease and orphan drug data base. Adultonset autosomal recessive cerebellar ataxia. ORPHA:284289

A rare, genetic, autosomal recessive cerebellar ataxia disease characterized by adulthood-onset of slowly progressive spinocerebellar ataxia, manifesting with gait and appendicular ataxia, dysarthria, ocular movement anomalies (e.g. horizontal, vertical, and/or downbeat nystagmus, hypermetric saccades), increased deep tendon reflexes and progressive cog nitive decline. Additional variable features may include proximal leg muscle wasting and fasciculations, pes cavus, inspiratory stridor, epilepsy, retinal degeneration and cataracts. Brain imaging reveals marked cerebellar atrophy and electromyography shows evidence of lower motor neuron involvement. 